\title{
Panel Data Modeling for Indian Food Grain Production
}

\author{
Rajarathinam. A $^{1} \&$ Suba. S.S ${ }^{2}$ \\ ${ }^{1,2}$ Department of Statistics, Manonmaniam Sundaranar University, Tirunelveli - 627 \\ 012, Tamil Nadu State, India \\ E-Mail: rajarathinam@msuniv.ac.in ${ }^{1}$ and sssuba@gmail.com ${ }^{2}$
}

\begin{abstract}
The present investigation was carried out to study the food grain production trends in selected states of India for the period 2001-02 to 2020-2021. In this study a panel data regression model is used to combat the complicated relations and strong auto-correlation present in the crop production time series data. Panel data modelling control the heterogeneity of cross-sectional units over time. The results reveal that between state-to-state food grain production is highly significant, the highest food grain production was registered in Uttar Pradesh, followed by Punjab and Madhya Pradesh. Very lowest was registered in Kerala and Himachal Pradesh. Levin, Lin \& Chu t statistics values are found to be significant indicating that the variable under study is stationary at level and hence the variable under study is I(O).Among the three different models viz., constant coefficient model, fixed effect model and random effect model, the fixed effect model was selected as an appropriate trend model as per the Hausman test. Based on the statistical significance of the estimated coefficients and the substantial increase in the $R^{2}$ value to $95 \%$, the fixed effect model or the least-square dummy variable regression model performs better than the panel least square regression model. The Hausman test confirms the selection of fixed effect over the random effect model. The fixed effects are positive in Andhra Pradesh, Karnataka, Kerala, Tamil Nadu, Gujarat, Chhattisgrah, Bihar, Haryana and Madhya Pradesh. Negative fixed effects are observed in Himachal Pradesh, Jharkhand, Maharashtra, Odisha, Punjab, Rajasthan, Uttar Pradesh, Uttarakhand and West Bengal. Increases in food grain production have been observed
\end{abstract}

Keywords: Panel Regression Model, Least-Squares Dummy Variable, Fixed-Effect Model, Random-Effect Model, Wald Test, Hausman Test.

Conflict of Interest: The authors have no conflicts of interest.

\section{Introduction}

Over the last few decades, regression modelling has traditionally been employed in agricultural production prediction and classification. For agricultural planning purposes, decision-makers need simple and reliable estimation techniques for crop production prediction. 
Multiple regressions, discriminant analysis, factor analysis, principal component analysis, cluster analysis and logistic regression analysis are the most commonly used statistical techniques for the prediction and classification of agricultural-related production. In agricultural production time series data, the problems of multicollinearity, autocorrelation and extreme values are unavoidable. In such complex situations, regression models may not provide accurate predictions. Regression models need to fulfil regression assumptions such as autocorrelation and multiple collinearity between the independent variables, which causes the estimated regression models to be unfit and the estimated parameter values obtained based on these models to be inefficient. In most agricultural practices, crop production is influenced by a great variety of interrelated factors, such as autocorrelation, and it is difficult to describe their relationships using conventional methods (Zaefizadah et al., [1]).

In this study, a panel data regression model is used to combat the complicated relations and strong autocorrelation present in the crop production data.

Panel data are a combination of cross-sectional and time series data. Therefore, using a regression suited to panel data has the advantage of distinguishing between fixed and random effects. Fixed effects are effects that are independent of random disturbances, e.g., observations independent of time. Random effects, effects that include random disturbances. Panel data are more informative since they include more information, but they have to be modeled correctly by taking into account fixed vs. random effects.

Panel data help us to control the heterogeneity of cross-sectional units such as individuals, states, firms, countries, etc., over time. Panel data estimation considers all crosssectional units to be heterogeneous. It helps us to get unbiased estimation. There are time invariant and state invariant variables that we observe or not. Compared to pure cross section and time series, panel data estimation is better for identifying and measuring the effects of independent variables on dependent variables, which we cannot measure using time series and cross section data. In addition, "Panel data give more informative data, more variability, less colinearity among the variables, more degree of freedom and more efficiency". It is also a better estimation method to study the duration of economic states and the "dynamics of change" over time. It is a good estimation method to 'construct and test complicated behavioral models' (Baltagi, [2]). 
Based on the above discussion, the present study aimed to study the trends in food grain production in different states in India over the period 2001-02 to 2020-2021 based on a panel regression model.

\section{Materials and Methods}

2.1. Materials: The present investigation was carried out to study the trends in food grin production in India based on a panel regression model. The cross-sectional time series data on food grain production for the period 2001-02 to 2020-2021 (twenty years) were collected from Reserve Bank of India - Handbook of Statistics on Indian Economy (rbi.org.in). Food grain production in eighteen states of India viz. Andhra Pradesh, Karnataka, Kerala, Tamil Nadu, Gujarat, Chhattisgarh, Bihar, Haryana, Himachal Pradesh, Jharkhand, Madhya Pradesh, Maharashtra, Odisha, Punjab, Rajasthan, Uttar Pradesh, Uttarakhand and West Bengal have been considered.

2.2. Methods: Panel data are a type of data that contain observations of multiple phenomena collected over different time periods for the same group of individuals, units, or entities. In short, econometric panel data are multidimensional data collected over a given period.

A simple panel data regression model is specified as

$$
Y_{i t}=\alpha+\beta X_{i t}+v_{i t}
$$

where $v_{i t}$ are the estimated residuals from the panel regression analysis. Here, $\mathrm{Y}$ is the dependent variable, $\mathrm{X}$ is the independent or explanatory variable, $\alpha$ and $\beta$ are the intercept and slope, $\mathrm{i}$ stands for the $\mathrm{i}^{\text {th }}$ cross-sectional unit and $\mathrm{t}$ for the $\mathrm{t}^{\text {th }}$ month, and $\mathrm{X}$ is assumed to be nonstochastic and the error term to follow classical assumptions, namely, $E\left(v_{i t}\right)=N\left(0, \sigma^{2}\right)$. In this study, $i$, the number of cross-sections is $18(\mathrm{i}=1,2,3,4, \ldots, 18)$, and $\mathrm{t}=1,2,3, \ldots, 20$. Detailed discussions of panel data models were given in Hsiao, [3], Greene, [4] and Gujarathi, [5].

2.2.1. Unit Root Test: Unit roots for the panel data can be tested using either the Leuin-LlinChu [6] test or the Hadri [7] LM stationarity test. The null hypothesis is that panels contain unit roots, and the alternative hypothesis is that panels are stationary. In the results, if the p value is less than 0.05, then one can reject the null hypothesis and accept the alternative hypothesis. Similarly, the unit root for the first difference can also be tested using a similar method.

2.2.2. Constant Coefficients Model: The Constant Coefficients Model (CCM) assumes that all coefficients (intercept and slope) remain unchanged across cross-sectional units and over 
time. In other words, the CCM ignores the space and time dimensions of panel data. Put differently, under the CCM, the cross-sectional units are assumed to be homogeneous such that the values of intercept and slope coefficients are the same irrespective of the cross-sectional unit being considered. Accepting this homogeneity assumption (also called the pooling assumption), the CCM uses the panel (or pooled) data set and applies the ordinary least squares (OLS) method to estimate unknown parameters of the model. Thus, the CCM is nothing but a straightforward application of OLS to a given panel or pooled data to obtain estimates for unknown parameters of the model (Bhaumik, [8]).

2.2.3. Individual Specific-Effect Model: Here, it is assumed that there is unobserved heterogeneity across individuals and captured by $\alpha_{i}$. The main question is whether the individual-specific effects $\alpha_{i}$ are correlated with the regressor; if they are correlated, a fixed effects model exists. If these factors are not correlated, a random effects model exists.

2.2.4. Fixed-Effect OR Least-Square Dummy Variable Regression Model: A fixed effect regression model indicates that each unit has its own intercept. There will be heterogeneity among the units due to individual intercepts. Here, in the fixed effect model, the unit intercepts are time-invariant (do not vary over time) even if they might be different among cross-sectional units. However, the fixed effect model believes that the coefficients of the independent variables do not vary across cross-sectional units or over time. These fixed effects models can be implemented with the dummy variable technique. Therefore, the fixed effects model can be written as

$$
Y_{i t}=\alpha_{1}+\alpha_{2} D_{2 i}+\alpha_{3 i} D_{3 i}+\alpha_{4} D_{4 i}+\ldots+\alpha_{18} D_{18 i}+\beta_{1} X_{i t}+v_{i t}
$$

where $D_{2 i}=1$ if the observation is from Karnataka state and is 0 otherwise, $D_{3 i}=1$ if the observation is from Kerala and is 0 otherwise, and $D_{4 i}=1$ if the observation is from Tamil Nadu and is 0 otherwise. Here, $\alpha_{1}$ represents the intercept of Andhra Pradesh, and $\alpha_{2}, \alpha_{3}$, and $\alpha_{4}$ are different intercept coefficients that indicate how much the intercepts of Karnataka, Kerala, and Tamil Nadu differ from that of Andhra Pradesh state. Since the dummies are used to estimate the fixed effects, the model is also known as the least-squares dummy variable (LSDV) model; hence, one can conclude that the restricted panel regression model is invalid and that the LSDV model is valid (Bhaumik, [8]). 
2.2.5. Random-Effect (RE) Model: The random effects model is also called the error component model (ECM). In this model, the cross-sectional units will have random intercepts instead of fixed intercepts. The rationale behind the random effects model is that, unlike the fixed effect model, the variation across entities is assumed to be random and uncorrelated with the predictor or independent variables included in the model. The crucial distinction between the fixed and random effects is whether the unobserved individual effects embody elements that are correlated with regressors in the model, not whether these effects are stochastic or not (Green, [4]). The RE model assumes that individual-specific effects ${ }_{i}^{\alpha_{i}}$ are random and that one should include ${ }^{\alpha_{i}}$ in the error term. Each cross-section has the same slope parameters and a composite error term. So the model (1) become Random-Effect Model (REM) :

$$
y_{i t}=x_{i t} \beta+\left(\alpha_{i}+v_{i t}\right)
$$

Let $\varepsilon_{i t}=\alpha_{i}+v_{i t}$.

Here, $\varepsilon_{i t}, \alpha_{i}$ and $v_{i}$ are normally distributed with zero means and constant variances $\sigma_{\varepsilon}^{2}, \sigma_{\alpha}^{2}$ and $\sigma_{v}^{2}$, respectively.

Hence : $\operatorname{var}\left(\varepsilon_{i t}\right)=\sigma_{\alpha}^{2}+\sigma_{v}^{2}$, and $\operatorname{cov}\left(\varepsilon_{i t}, \varepsilon_{i s}\right)=\sigma_{\alpha}^{2}$; therefore, $\rho_{\varepsilon}=\operatorname{cor}\left(\varepsilon_{i t}, \varepsilon_{i s}\right)=\frac{\sigma_{\alpha}^{2}}{\sigma_{\alpha}^{2}+\sigma_{\varepsilon}^{2}}$.

Rho is the interclass correlation of the error or the fraction of the variance in the error term due to individual-specific effects. These variables approach 1 if individual effects dominate the idiosyncratic error (Bhaumik, [8]).

2.2.6. Hausman test: The Hausman test (Hasman, [9]) is the standard procedure used in empirical panel data analysis to distinguish between fixed effects and random effects. In the Hausman test, the null hypothesis signifies that there is no significant difference in the estimator of the fixed effect model and random effect model. If we reject the null hypothesis, the fixed effect model will be the appropriate model. Rejecting the null hypothesis shows that there might be a correlation between the error term and dependent variable. The test statistic can be calculated as follows:

$$
H=\left(\widehat{\beta}_{R E}-\widehat{\beta}_{F E}\right)^{l}\left(V\left(\widehat{\beta}_{R E}\right)-V\left(\widehat{\beta}_{F E}\right)\right)\left(\widehat{\beta}_{R E}-\widehat{\beta}_{F E}\right)
$$

Here, $\widehat{\beta}_{R E}$ and $\widehat{\beta}_{F E}$ are the vector of parameter estimates of random effects and fixed effects, respectively. Under the null hypothesis, this statistic asymptotically has a chi-squared distribution with the number of degrees of freedom equal to the rank of the matrix : 


$$
\left(V\left(\widehat{\beta}_{R E}\right)-V\left(\widehat{\beta}_{F E}\right)\right)
$$

2.2.7. Wald Test: The Wald test (Wald, [10]) can determine which model variables make significant contributions. The Wald test (also called the Wald chi-squared test) is a way to determine if explanatory variables in a model are significant, meaning that they add something to the model; variables that add nothing can be deleted without affecting the model in a meaningful way. The test can be used for a multitude of different models, including those with binary variables or continuous variables. The null hypothesis for the test is: some parameter $=$ some value.

2.2.8. Breusch-Pagan Lagrange Multiplier Test: The Breusch-Pagan-Godfrey test (Breusch and Pagan, [11]) is a Lagrange multiplier test of the null hypothesis of no heteroskedasticity, i.e., constant variance among residuals.

Ho: The null hypothesis of the test states that there is constant variance among residuals.

\section{RESULTS AND DISCUSSION}

The results obtained in this paper based on applying different statistical tools related to panel regression models are discussed in subsequent sections.

3.1. Summary Statistics: The descriptive statistics results presented in Table 1 and depicted in Fig. 1 reveal that state wise food grain production is normally distributed, as indicated by Jarque-Bera statistic p-values, except for the states Himachal Pradesh and Odisha. The highest food grain production was registered in Uttar Pradesh, followed by Punjab and Madhya Pradesh. The lowest production is registered in Kerala and Himachal Pradesh. Fig. 2 shows that the highest food grain production was registered during 2018-2019, and the year wise production showed an increasing trend.

Table 1: State wise Food Grain Production Details

\begin{tabular}{|c|l|r|r|r|r|r|c|}
\hline Sr.No. & Name of State & \multicolumn{1}{c|}{ Sum } & \multicolumn{1}{c|}{ Mean } & \multicolumn{1}{c|}{ Max. } & \multicolumn{1}{c|}{ Mini. } & \multicolumn{1}{c|}{ S.D } & $\begin{array}{c}\text { Jarque- } \\
\text { Bera } \\
\text { Prob. }\end{array}$ \\
\hline 1 & Andhra Pradesh & 303003.00 & 15150.15 & 20421.00 & 10365.40 & 3572.47 & 0.4094 \\
\hline 2 & Bihar & 253527.60 & 12676.38 & 17036.90 & 7704.40 & 2737.38 & 0.6372 \\
\hline 3 & Chhattisgarh & 129993.00 & 6499.65 & 9324.10 & 3274.70 & 1366.25 & 0.8944 \\
\hline 4 & Gujarat & 139058.80 & 6952.94 & 9179.60 & 3566.30 & 1446.41 & 0.7472 \\
\hline 5 & Haryana & 314500.40 & 15725.02 & 18274.20 & 12328.90 & 1886.79 & 0.4766 \\
\hline 6 & Himachal Pradesh & 29545.90 & 1477.30 & 1740.60 & 1017.20 & 170.97 & 0.0408 \\
\hline 7 & Jharkhand & 75343.20 & 3767.16 & 6001.30 & 1876.60 & 1301.33 & 0.5478 \\
\hline
\end{tabular}




\begin{tabular}{|c|l|r|r|r|r|r|r|}
8 & Karnataka & 220384.00 & 11019.20 & 14187.00 & 6562.10 & 2081.62 & 0.4980 \\
\hline 9 & Kerala & 11739.30 & 586.97 & 718.90 & 439.00 & 70.08 & 0.9303 \\
\hline 10 & Madhya Pradesh & 425622.00 & 21281.10 & 33523.10 & 10748.80 & 8469.48 & 0.3126 \\
\hline 11 & Maharashtra & 246466.90 & 12323.35 & 16069.20 & 8754.40 & 2034.96 & 0.6186 \\
\hline 12 & Odisha & 151779.00 & 7588.95 & 9459.00 & 3573.70 & 1280.89 & 0.0013 \\
\hline 13 & Punjab & 551900.70 & 27595.04 & 31691.90 & 23491.20 & 2260.11 & 0.7910 \\
\hline 14 & Rajasthan & 342927.50 & 17146.38 & 24313.10 & 7536.00 & 4165.03 & 0.6823 \\
\hline 15 & Tamil Nadu & 159365.50 & 7968.28 & 11478.50 & 4141.60 & 2423.01 & 0.5525 \\
\hline 16 & Uttar Pradesh & 931735.50 & 46586.78 & 58313.30 & 37836.30 & 5906.19 & 0.5973 \\
\hline 17 & Uttarakhand & 35634.70 & 1781.74 & 2003.50 & 1559.10 & 107.42 & 0.9087 \\
\hline 18 & West Bengal & 333035.80 & 16651.79 & 20106.70 & 14466.90 & 1250.53 & 0.0892 \\
\hline
\end{tabular}

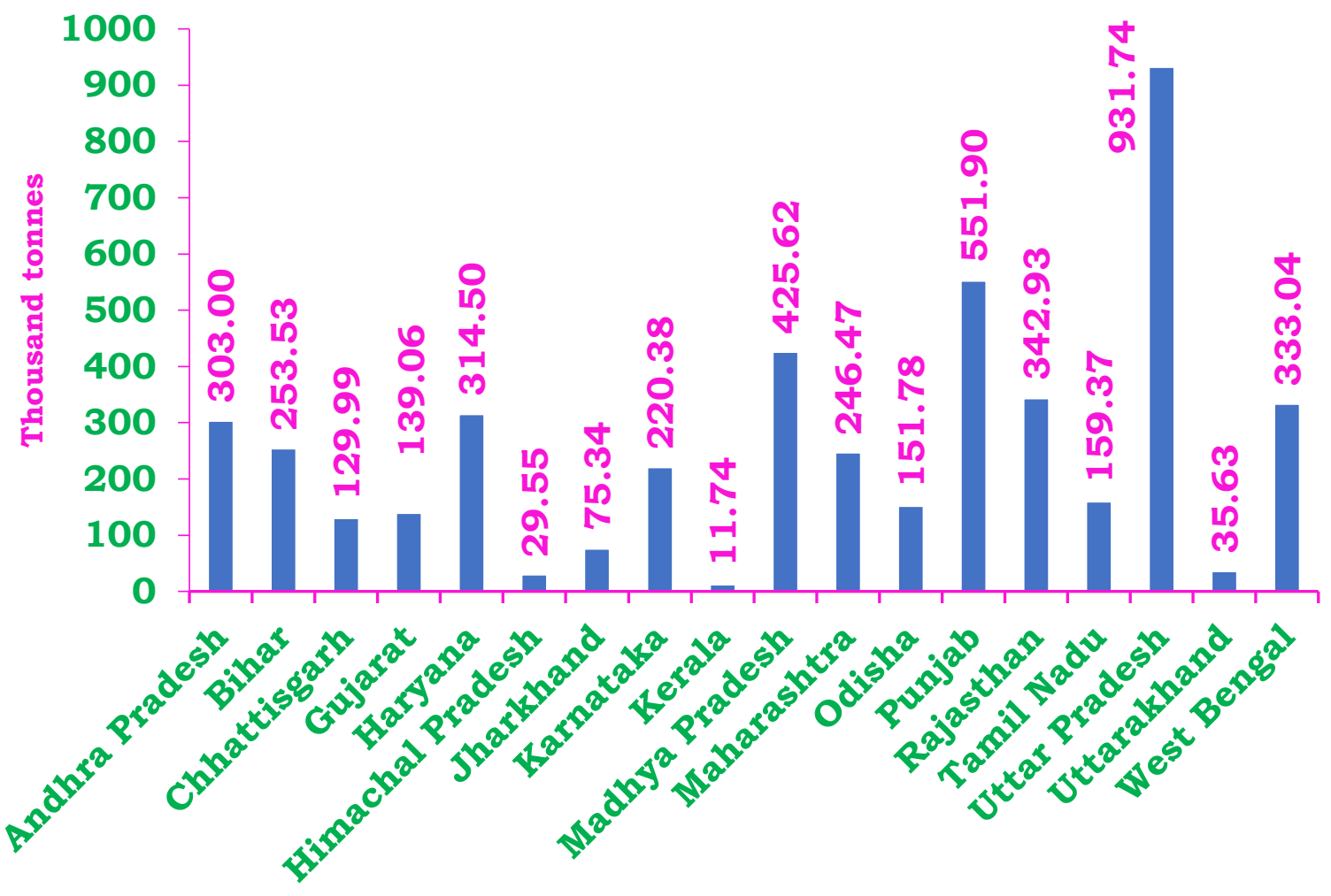

Fig.1. State wise Food Grain Production 


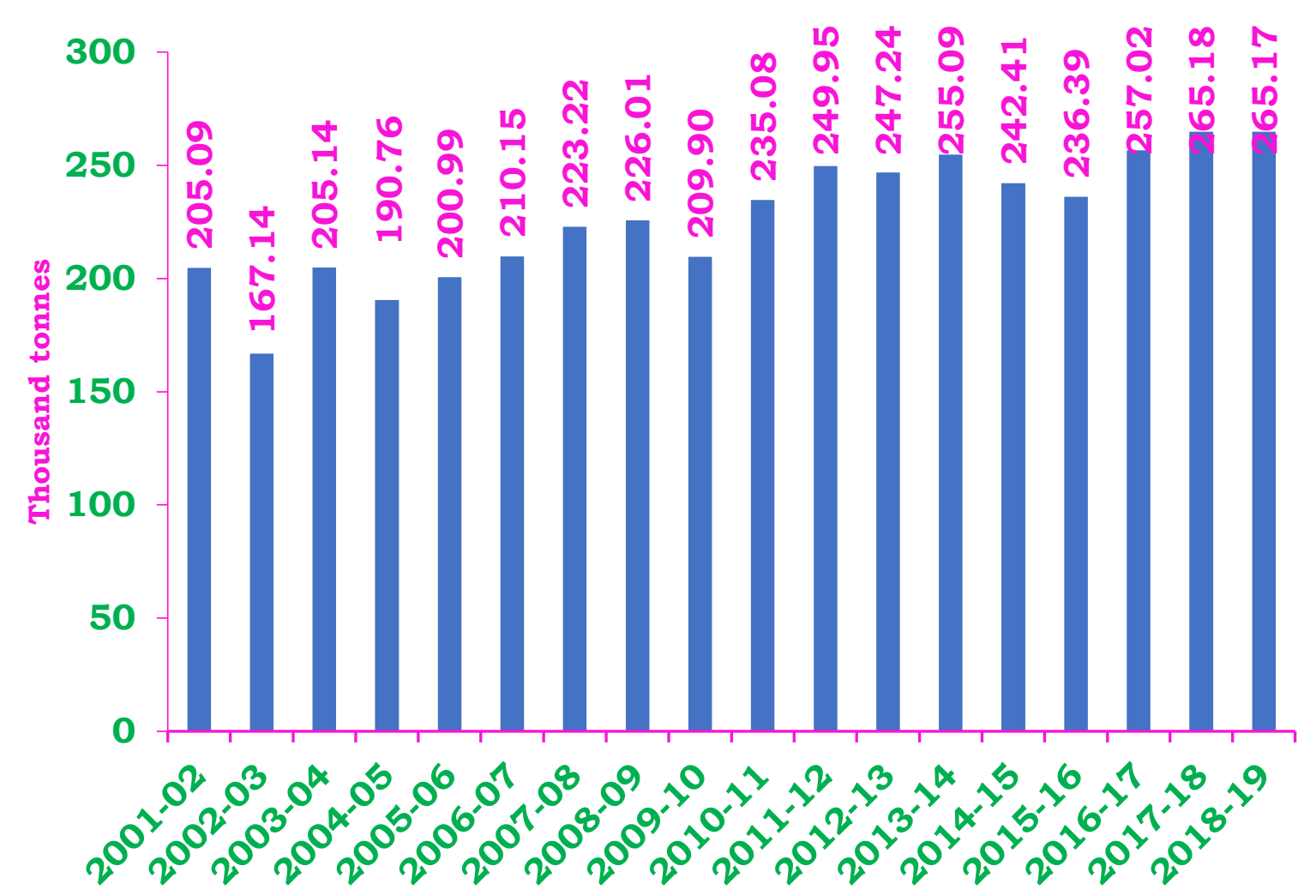

Fig.2. Year wise Food Grain Production

The results presented in Table 2 reveal that the ANOVA F-test and Welch F-test statistic's value values are significant, indicating that production is statistically significant in all states.

Table 2: Analysis of variance test for equality of production means

\begin{tabular}{lccc}
\hline \multicolumn{1}{c}{ Method } & Df & Value & Probability \\
\hline Anova F-test & $(17,342)$ & 251.0402 & 0.0000 \\
Welch F-test* & $(17,124.252)$ & 744.1693 & 0.0000 \\
\hline
\end{tabular}

*Test allows for unequal cell variances

Analysis of Variance

\begin{tabular}{lccc}
\hline \multicolumn{1}{c}{ Source of Variation } & Df & Sum of Sq. & Mean Sq. \\
\hline Between & 17 & $4.18 \mathrm{E}+10$ & $2.46 \mathrm{E}+09$ \\
Within & 342 & $3.35 \mathrm{E}+09$ & 9785232. \\
\hline Total & 359 & $4.51 \mathrm{E}+10$ & $1.26 \mathrm{E}+08$ \\
\hline
\end{tabular}

Unit Root Test: Before estimating the panel data regression model, it is necessary to determine the stationarity of the variable under study.

The unit root test result presented in Table 3 reveals that since the Levin, Lin \& Chu $t$ statistics values are significant at the $1 \%$ level of significance since the p-value is 0.0001 and hence the study variable, PROD, is stationary at the level and hence the variable is $\mathrm{I}(0)$. 
Table 3: Characteristics of the unit root test

\begin{tabular}{ccccc}
\hline Method & \multicolumn{2}{c}{ Individual Effect } & \multicolumn{2}{c}{ Individual effects, linear trends } \\
\cline { 2 - 5 } & Statistic & Prob. $^{* *}$ & Statistic & Prob. $^{* *}$ \\
\hline Levin, Lin \& Chu t* & 3.05481 & 0.0011 & 9.12116 & 0.0000 \\
\hline
\end{tabular}

** Probabilities are computed assuming asymptotic normality.

Constant Coefficient Model (Panel OLS): The CCM es method is employed considering food grain production (PRODN) as the dependent variable and $\mathrm{X}$, time, as the independent variables; the results are presented in Table 4. The result reveals that the intercepts and slopes are positive and highly significant at the $1 \%$ level of significance. The positive slope indicates that food grain production is an increasing trend. The model is highly significant at the $1 \%$ level of significance with an incredibly low $\mathrm{R}^{2}$ value of $15 \%$, which is very low. Additionally, the estimated Durbin-Watson value of 0.043090 is quite low, which suggests the presence of autocorrelation in the data.

Table 4: Characteristics of the fitted panel least-squares method

\begin{tabular}{lrlrr}
\hline \multicolumn{1}{c}{ Variable } & Coefficient & Std. Error & t-Statistic & Prob. \\
\multicolumn{1}{c}{ C } & 5384.438 & 1092.674 & 4.927761 & 0.0000 \\
X & 41.81541 & 5.246203 & 7.970603 & 0.0000 \\
\hline Root MSE & 10315.66 & R-squared & & 0.150714 \\
Mean dependent var & 12932.12 & Adjusted R-squared & 0.148342 \\
S.D. dependent var & 11209.18 & S.E. of regression & 10344.43 \\
Akaike info criterion & 21.33182 & Sum squared resid & $3.83 \mathrm{E}+10$ \\
Schwarz criterion & 21.35341 & Log likelihood & & -3837.728 \\
Hannan-Quinn criter. & 21.34041 & F-statistic & & 63.53052 \\
Durbin-Watson stat & 0.043090 & Prob(F-statistic) & & 0.000000 \\
\hline
\end{tabular}

The estimated model assumes that the slope coefficients of time variables $\mathrm{X}$ are all identical in all eighteen states. Therefore, despite its simplicity, the CCM may distort the true relationship between the dependent variable — food grain production (PRODN) - and time, the independent variable $\mathrm{X}$, across the states.

Fixed-Effect OR Least-Square Dummy Variable Regression Model: The result presented in Table 5 reveals that the fixed effect model explains $82 \%$ of the variation in the dependent variable. The model is highly significant at the $1 \%$ level of significance. All the dummy variables were also highly significant at the $1 \%$ level of significance. The root mean square error is 2609.55 with the S.E. of regression is 2681.27. 
Based on the statistical significance at the $1 \%$ level of significance of the estimated coefficients and the substantial increase in the $\mathrm{R}^{2}$ value to $95 \%$ (significant at the $1 \%$ level of significance), one can conclude that the fixed effects model or the LSDSV regression model performs better than the panel least-squares regression model (CCM).

Table 5: Characteristics of the fixed effects or LSDSV regression model

\begin{tabular}{|c|c|c|c|c|}
\hline \multicolumn{5}{|c|}{$\begin{array}{l}\text { PRODN }=\mathrm{C}(1)+\mathrm{C}(2) * \mathrm{X}+\mathrm{C}(3) *(\mathrm{D} 2)+\mathrm{C}(4) *(\mathrm{D} 3)+\mathrm{C}(5) *(\mathrm{D} 4)+\mathrm{C}(6) *(\mathrm{D} 5)+\mathrm{C}(7) \\
\quad *(\mathrm{D} 6)+\mathrm{C}(8) *(\mathrm{D} 7)+\mathrm{C}(9) *(\mathrm{D} 8)+\mathrm{C}(10) *(\mathrm{D} 9)+\mathrm{C}(11)^{*}(\mathrm{D} 10)+\mathrm{C}(12) *(\mathrm{D} 11) \\
\quad+\mathrm{C}(13) *(\mathrm{D} 12)+\mathrm{C}(14) *(\mathrm{D} 13)+\mathrm{C}(15) *(\mathrm{D} 14)+\mathrm{C}(16) *(\mathrm{D} 15)+\mathrm{C}(17) *(\mathrm{D} 16) \\
+\mathrm{C}(18) *(\mathrm{D} 17)+\mathrm{C}(19) *(\mathrm{D} 18)\end{array}$} \\
\hline & Coefficient & Std. Error & t-Statistic & Prob. \\
\hline $\mathrm{C}(1)$ & 12278.95 & 652.44 & 18.82 & 0.0000 \\
\hline $\mathrm{C}(2)$ & 273.45 & 24.51 & 11.15786 & 0.0000 \\
\hline $\mathrm{C}(3)$ & -9599.90 & 979.37 & -9.802151 & 0.0000 \\
\hline $\mathrm{C}(4)$ & -25501.08 & 1296.10 & -19.67522 & 0.0000 \\
\hline $\mathrm{C}(5)$ & -23588.71 & 1697.37 & -13.89718 & 0.0000 \\
\hline$C(6)$ & -30073.00 & 2136.06 & -14.07871 & 0.0000 \\
\hline$C(7)$ & -35995.23 & 2593.25 & -13.88038 & 0.0000 \\
\hline $\mathrm{C}(8)$ & -35287.45 & 3060.65 & -11.52941 & 0.0000 \\
\hline $\mathrm{C}(9)$ & -37707.76 & 3534.22 & -10.66934 & 0.0000 \\
\hline $\mathrm{C}(10)$ & -57424.43 & 4011.77 & -14.31400 & 0.0000 \\
\hline $\mathrm{C}(11)$ & -60603.51 & 4492.03 & -13.49133 & 0.0000 \\
\hline $\mathrm{C}(12)$ & -48558.52 & 4974.23 & -9.762025 & 0.0000 \\
\hline $\mathrm{C}(13)$ & -62985.22 & 5457.84 & -11.54033 & 0.0000 \\
\hline$C(14)$ & -73188.56 & 5942.52 & -12.31609 & 0.0000 \\
\hline $\mathrm{C}(15)$ & -58651.42 & 6428.02 & -9.124332 & 0.0000 \\
\hline$C(16)$ & -74569.03 & 6914.19 & -10.78493 & 0.0000 \\
\hline $\mathrm{C}(17)$ & -50597.57 & 7400.87 & -6.836703 & 0.0000 \\
\hline $\mathrm{C}(18)$ & -100871.60 & 7887.99 & -12.78799 & 0.0000 \\
\hline $\mathrm{C}(19)$ & -91470.45 & 8375.46 & -10.92125 & 0.0000 \\
\hline Root MSE & 2609.550 & R-squared & & 0.945651 \\
\hline Mean dependent var & 12932.12 & Adjusted R-squared & & 0.942782 \\
\hline S.D. dependent var & 11209.18 & S.E. of regression & & 2681.265 \\
\hline Akaike info criterion & 18.67730 & Sum squared resid & & $2.45 E+09$ \\
\hline Schwarz criterion & 18.88240 & Log likelihood & & -3342.914 \\
\hline Hannan-Quinn criter. & 18.75885 & F-statistic & & 329.6257 \\
\hline Durbin-Watson stat & 0.667659 & Prob(F-statistic) & & 0.000000 \\
\hline
\end{tabular}

The cross-sectional fixed effects (as deviations from the common intercept) in the context of the fixed effect model are calculated and presented in Table 6 . The fixed effects are positive in Andhra Pradesh, Karnataka, Kerala, Tamil Nadu, Gujarat, Chhattisgarh, Bihar, Haryana and Madhya Pradesh. The fixed effect is negative in Himachal Pradesh, Jharkhand, Maharashtra, Odisha, Punjab, Rajasthan, Uttar Pradesh, Uttarakhand, and West Bengal. In Andhra Pradesh, the fixed effect is 48704.08 , which is highest in comparison to that in other states. 
Table 6: Cross-Section Fixed Effects Values

\begin{tabular}{ccc}
\hline Sr.No. & CROSSID & Effect \\
\hline 1 & 1 & 48704.08 \\
2 & 2 & 39104.18 \\
3 & 3 & 23203.00 \\
4 & 4 & 25115.36 \\
5 & 5 & 18631.08 \\
6 & 6 & 12708.84 \\
7 & 7 & 13416.63 \\
8 & 8 & 10996.32 \\
9 & 9 & -8720.35 \\
10 & 10 & -11899.43 \\
11 & 11 & 145.56 \\
12 & 12 & -14281.14 \\
13 & 13 & -24484.48 \\
14 & 14 & -9947.343 \\
15 & 15 & -25864.95 \\
16 & 16 & -1893.496 \\
17 & 17 & -52167.48 \\
18 & 18 & -42766.37 \\
\hline
\end{tabular}

The diagrammatic representation of fixed effects in all eighteen states is depicted in Fig. 3.

Based on this result, it is concluded that the fixed effect model is better than CCM.

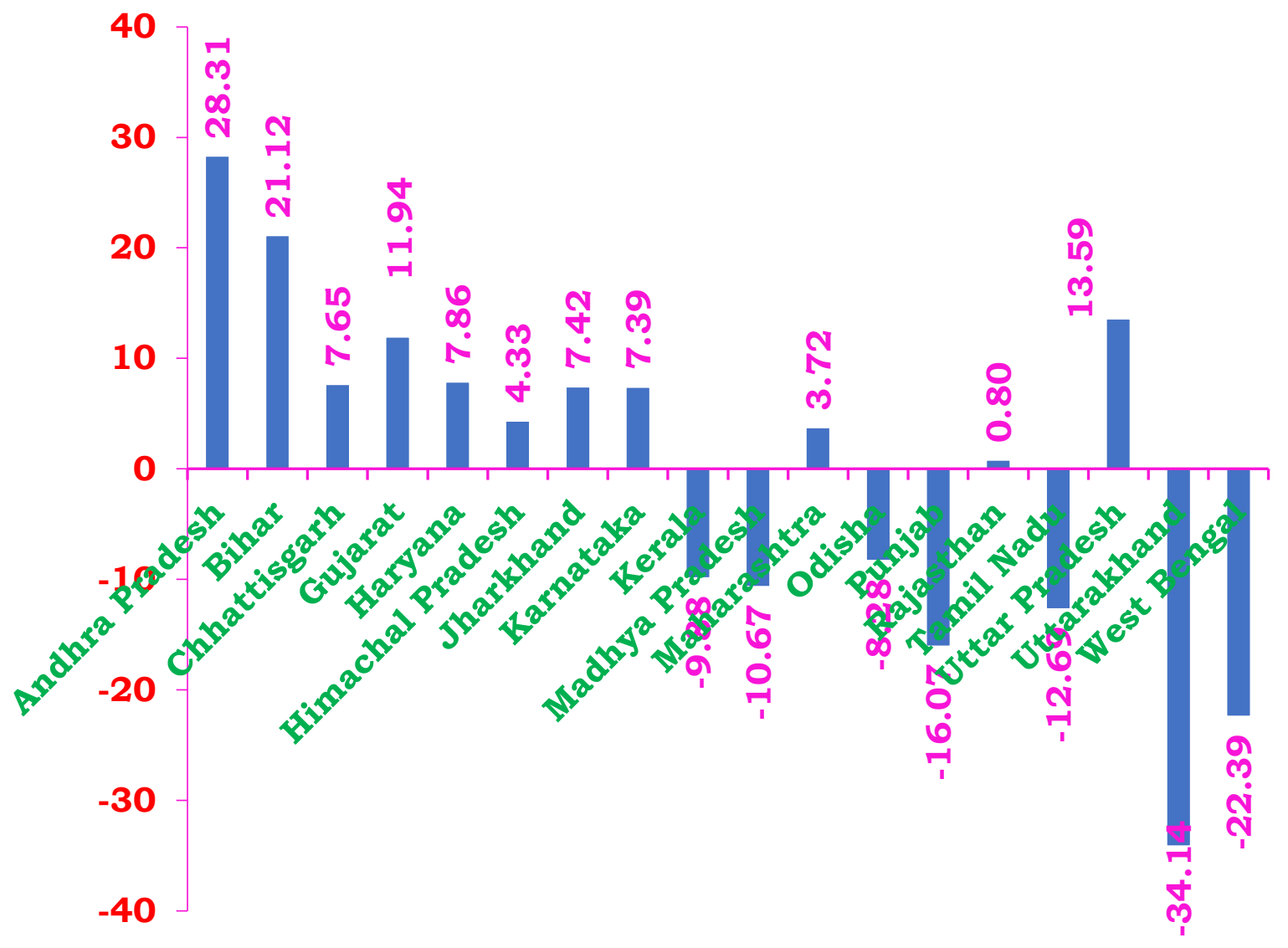

Fig.3. Fixed effect in different states 
To confirm the presence of the fixed effect, the redundant fixed effect test was carried out, and the results are presented in Table 7.

Table 7: Results of Redundant Fixed Effects Test

Redundant Fixed Effects Tests

\begin{tabular}{lrrr}
\hline Effects Test & Statistic & d.f. & Prob. \\
\hline Cross-section F & 293.390789 & $(17,341)$ & 0.0000 \\
Cross-section Chi-square & 989.629016 & 17 & 0.0000 \\
\hline
\end{tabular}

$\underline{\mathrm{PRODN}}=\mathrm{C}(1)+\mathrm{C}(2) * \mathrm{X}$

\begin{tabular}{rrlrr}
\hline & Coefficient & \multicolumn{1}{c}{ Std. Error } & t-Statistic & Prob. \\
\hline C $(1)$ & 5384.438 & 1092.674 & 4.927761 & 0.0000 \\
C(2) & 41.81541 & 5.246203 & 7.970603 & 0.0000 \\
\hline Root MSE & 10315.66 & R-squared & & 0.150714 \\
Mean dependent var & 12932.12 & Adjusted R-squared & 0.148342 \\
S.D. dependent var & 11209.18 & S.E. of regression & & 10344.43 \\
Akaike info criterion & 21.33182 & Sum squared resid & & $3.83 \mathrm{E}+10$ \\
Schwarz criterion & 21.35341 & Log likelihood & & -3837.728 \\
Hannan-Quinn criter. & 21.34041 & F-statistic & & 63.53052 \\
Durbin-Watson stat & 0.043090 & Prob(F-statistic) & & 0.000000 \\
\hline
\end{tabular}

The test results reveal that the Cross-section $\mathrm{F}$ and Chi-square statistic values are significant at the $1 \%$ level of significance, indicating that the presence of fixed effects is different from one state to another.

Wald Test: To compare the fixed effect model with CCM, the Wald test was carried out. The null hypothesis of the Wald test is $\mathrm{H}_{0}=\mathrm{C}(3)=\mathrm{C}(4)=\mathrm{C}(5) \ldots=\mathrm{C}(18)=0$, i.e., All three dummy variable values are zero (there is no fixed effect). The result presented in Table 8 reveals that since the $\mathrm{F}$ and chi-square statistics values are significant at the $1 \%$ level of significance, the null hypothesis $\mathrm{H}_{0}=\mathrm{C}(3)=\mathrm{C}(4)=\mathrm{C}(5)=\ldots=\mathrm{C}(18)=0$ is rejected, which indicates that the values of the dummy variables are not equal to zero, which confirms fixed effects, or the LSDV regression model is an appropriate model in comparison to CCM.

Table 8: Characteristics of the Wald test

\begin{tabular}{lccc}
\hline Test Statistic & Value & df & Probability \\
\hline F-statistic & 292.7218 & $(16,341)$ & 0.0000 \\
Chi-square & 4683.549 & 16 & 0.0000 \\
\hline
\end{tabular}

Null Hypothesis: $C(3)=C(4)=C(5)=C(6)=C(7)=C(8)=C(9)=C($

$10)=\mathrm{C}(11)=\mathrm{C}(12)=\mathrm{C}(13)=\mathrm{C}(14)=\mathrm{C}(15)=\mathrm{C}(16)=\mathrm{C}(17)=\mathrm{C}($

$18)=\mathrm{C}(19)$

Null Hypothesis Summary:

\begin{tabular}{lcc}
\hline Normalized Restriction (= 0) & Value & Std. Err. \\
\hline C(3) - C(19) & 81870.55 & 7887.99 \\
C(4) - C (19) & 65969.37 & 7400.87
\end{tabular}




$\begin{array}{lcc}C(5)-C(19) & 67881.74 & 6914.19 \\ C(6)-C(19) & 61397.45 & 6428.02 \\ C(7)-C(19) & 55475.22 & 5942.52 \\ C(8)-C(19) & 56183.00 & 5457.84 \\ C(9)-C(19) & 53762.70 & 4974.23 \\ C(10)-C(19) & 34046.02 & 4492.03 \\ C(11)-C(19) & 30866.94 & 4011.77 \\ C(12)-C(19) & 42911.94 & 3534.22 \\ C(13)-C(19) & 28485.23 & 3060.65 \\ C(14)-C(19) & 18281.89 & 2593.25 \\ C(15)-C(19) & 32819.03 & 2136.06 \\ C(16)-C(19) & 16901.42 & 1697.37 \\ C(17)-C(19) & 40872.88 & 1296.10 \\ C(18)-C(19) & -9401.19 & 979.37\end{array}$

Restrictions are linear in coefficients.

Random-Effect Model: Finally, the random-effect model was estimated, and the results are presented in Table 9. The results reveal that the model is highly significant at the $1 \%$ level of significance with a low $\mathrm{R}^{2}$ value of $17 \%$ with an S.E. of regression 2845.515, RMSE, 2837.60. As in the case of the fixed effect model, the random-effect model's intercept and slope are highly significant at the $1 \%$ level of significance. The rho value is 0.9385 , which indicates that the individual effects of cross-sections are $0.9 \%$.

Table 9: Characteristics of the fitted random effects model

\begin{tabular}{|c|c|c|c|c|}
\hline Variable & Coefficient & Std. Error & t-Statistic & Prob. \\
\hline $\mathrm{C}$ & -14867.17 & 3952.539 & -3.761424 & 0.0002 \\
\hline$X$ & 154.0127 & 17.08422 & 9.014909 & 0.0000 \\
\hline \multicolumn{5}{|c|}{ Effects Specification } \\
\hline & & & S.D. & Rho \\
\hline Cross-section random & & & 10472.86 & 0.9385 \\
\hline Idiosyncratic random & & & 2681.265 & 0.0615 \\
\hline \multicolumn{5}{|c|}{ Weighted Statistics } \\
\hline Root MSE & 2837.599 & R-squared & & 0.167746 \\
\hline Mean dependent var & 739.1265 & Adjusted R-squared & & 0.165422 \\
\hline S.D. dependent var & 3114.779 & S.E. of regression & & 2845.515 \\
\hline Sum squared resid & $2.90 \mathrm{E}+09$ & F-statistic & & 72.15735 \\
\hline Durbin-Watson stat & 0.565478 & Prob(F-statistic) & & 0.000000 \\
\hline \multicolumn{5}{|c|}{ Unweighted Statistics } \\
\hline$\overline{\mathrm{R} \text {-squared }}$ & -0.934325 & Mean dependent var & & 12932.12 \\
\hline Sum squared resid & $8.73 E+10$ & Durbin-Watson stat & & 0.018787 \\
\hline
\end{tabular}

The cross-sectional random effects in the context of the random effect model are calculated and presented in Table 10. The random effects are positive in Andhra Pradesh, Karnataka, Kerala, Tamil Nadu, Gujarat, Chhattisgarh, Bihar, Haryana and Madhya Pradesh 
and Punjab. The random effects are negative in Himachal Pradesh, Jharkhand, Maharashtra, Odisha, Rajasthan, Uttar Pradesh, Uttarakhand, and West Bengal.

Table 10: Cross-Section Random Effects Values

\begin{tabular}{ccc}
\hline Sr.No. & CROSSID & Effect \\
\hline 1 & 1 & 28307.42 \\
2 & 2 & 21119.77 \\
3 & 3 & 7651.421 \\
4 & 4 & 11938.43 \\
5 & 5 & 7856.217 \\
6 & 6 & 4334.215 \\
7 & 7 & 7420.576 \\
8 & 8 & 7389.066 \\
9 & 9 & -9882.309 \\
10 & 10 & -10670.12 \\
11 & 11 & 3716.420 \\
12 & 12 & -8282.265 \\
13 & 13 & -16071.39 \\
14 & 14 & 799.1541 \\
15 & 15 & -12685.57 \\
16 & 16 & 13588.47 \\
17 & 17 & -34140.40 \\
18 & 18 & -22389.11 \\
\hline
\end{tabular}

The diagrammatic representation of the random effect in all eighteen states is depicted in Fig. 4. Based on this result, the presence of random effects in all four different districts is confirmed.

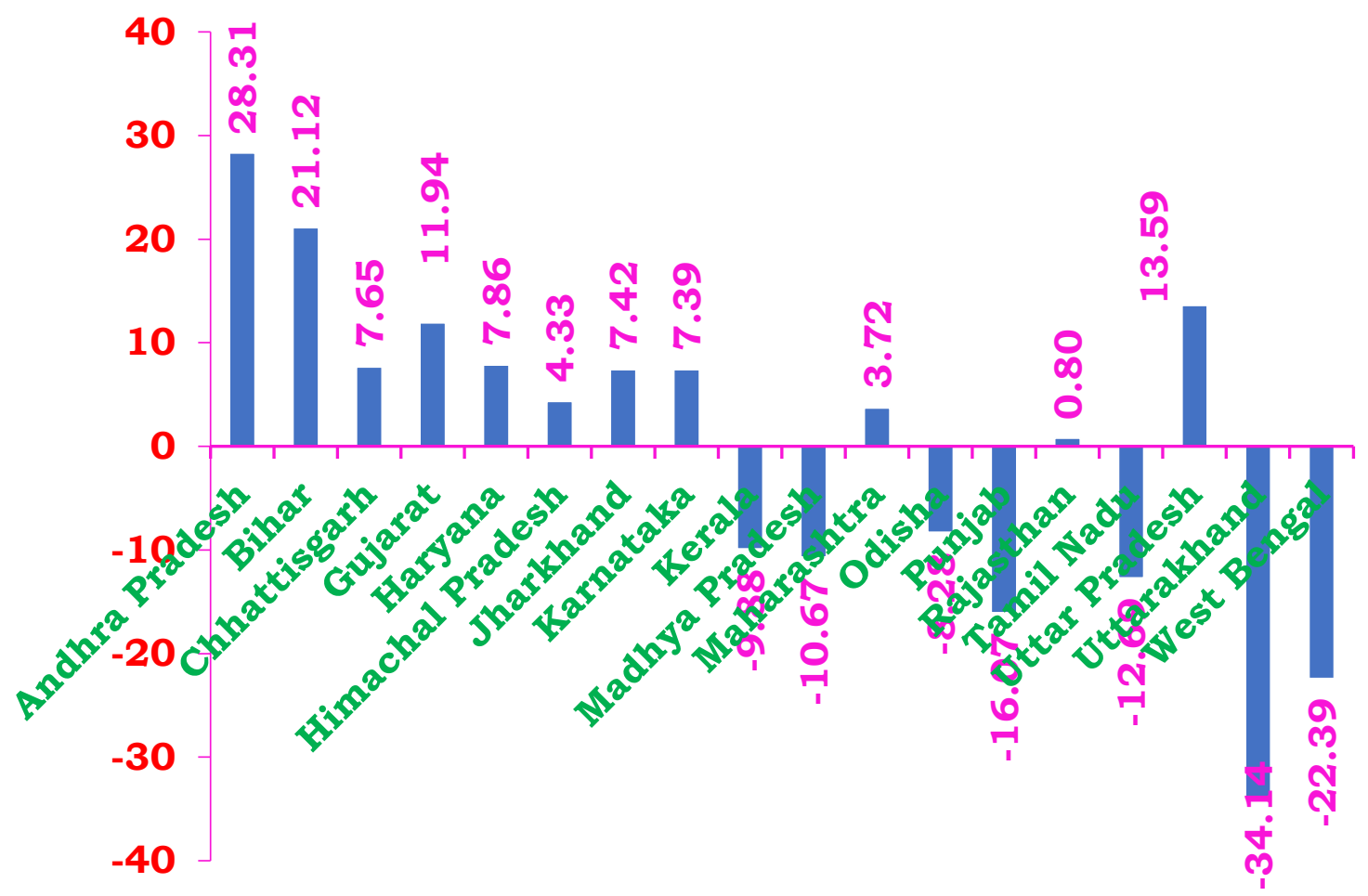

Fig.4. Random effect in different districts 


\section{Breusch-Pagan Lagrange-Multiplier Test:}

The result presented in Table 11 indicates that the Breusch-Pagan LM, Pesaran scaled LM and Pesaran CD test statistic values are highly significant at the $1 \%$ level of significance since both statistical p-values are equal to 0.0000 , indicating that the null hypothesis of the test, " $\mathrm{H}_{0}$ : There is constant variance among residuals", is rejected. Hence, the above random effect model has the problem of heteroscedasticity.

Table 11: Characteristics of the residual cross-section dependence test

\begin{tabular}{lcrr}
\hline \multicolumn{1}{c}{ Test } & Statistic & d.f. & Prob. \\
\hline Breusch-Pagan LM & 566.0751 & 153 & 0.0000 \\
Pesaran scaled LM & 23.61393 & & 0.0000 \\
Pesaran CD & 3.092296 & & 0.0020 \\
\hline
\end{tabular}

Hausman Test: The Hausman test result presented in Table 12 reveals that as the ChiSq.statistics value 0.0000 with 1 degree of freedom is highly significant at the $1 \%$ level of significance, the null hypothesis " $\mathrm{H}_{0}:$ Random Effect Model" is rejected. So, among the three models viz. CCM, fixed effect and random effect models have emerged as appropriate models.

Table 12: Characteristics of the Hausman Test

\begin{tabular}{lccc}
\hline Test Summary & Chi-Sq. Statistic & Chi-Sq.D.F. & Prob. \\
\hline Cross-Section Random & 46.2043 & 1 & 0.0000 \\
\hline
\end{tabular}

Fig. 5 depicts and confirms that the coefficients of intercept and slope lie in the $99 \%$ confidence interval (CI)

\section{Conclusion}

The present investigation was carried out to study the food grain production trends in different states in India based on a panel regression model for the period 2001-02 to 2020-2021. The results reveal that between state-to-state food, grain production is highly significant, and the highest food grain production was registered in Uttar Pradesh, followed by Punjab and Madhya Pradesh. Very lowest was registered in Kerala and Himachal Pradesh. The fixed effect model was found to study the trend, and this model explains $82 \%$ of the variation in food grain production. Increases in food grain production have been observed. 


\section{REFERENCES}

[1] Zaefizadah M., Khayatnezhad M. and Ghlaomin M., Comparison of Multiple Linear Regression (MLR) and Artificial Neural Network (ANN) in Predicting the Yield Using its Components in the Hulless Barley, J. Agriculture and Environmental Sciences, 10(1), (2011), 60-64.

[2] Baltagi, B.H., Econometric Analysis of Panel Data.6th Edition, Wiley, New York, NY, https://link.springer.com/book/10.1007\%2F978-3-030-53953-5, (2021).

[3] Hsiao, C., Analysis of Panel Data. Cambridge University Press, Cambridge, (2003).

[4] Greene, W.H., Econometric Analysis, Pearson Prentice Hall, Upper Saddle River, NJ, (2008).

[5] Gujarati, D.N., D.C.Porter, G.Sangeetha, Basic Econometrics, $5^{\text {th }}$ edition. McGraw Hill Education, New York, NY, (2017).

[6] Levin, A., C.F. Lin, and C.S.J.Chu, Unit Root Tests in Panel Data: Asymptotic and Finite-Sample Properties. Journal of Econometrics, 108, (2002), 1-24.

[7] Hadri, K., Testing for Units Roots in Heterogeneous Panel Data. Econometrics Journal, 3 (2000), 148-161.

[8] Bhaumik, S.K., Principles of Econometrics, $2^{\text {nd }}$ edition, Oxford University Press, (2017).

[9] Hausman, J. A., Specification Tests in Econometrics, Econometrica, 46, (1978), 12511272.

[10] Wald, A, Test of statistical hypotheses concerning several parameters when the number of observations is large, Transactions of the American Mathematical Society, 54, (1943), 426-482, http://www.jstor.org/stable/1990256.

[11] Breusch, T., and A. Pagan The Lagrange Multiplier Test and its Application to Model Specification in Econometrics, Review of Economic Studies, 47, (1980), 239-253. 